\title{
COMPOSITE MEMBRANE BASED ON SULFONATED POLYSULFONE-NATURAL ZEOLITE-TITANIUM DIOXIDE
}

\author{
I. Gustian* and Ghufira and D. Oktiarni \\ Department of Chemistry, Faculty of Mathematics and Natural Sciences \\ Universitas Bengkulu, Jalan Raya Kandang Limun, Bengkulu 38371, Indonesia \\ *E-mail: Irfan.g@unib.ac.id
}

\begin{abstract}
Composite membrane based on sulfonated polysulfone-natural zeolite-titanium dioxide has been performed. The composite membrane is carried out by mixing the sulfonated polysulfone with natural zeolite, with the mass ratio of sulfonated polysulfone: zeolite; 1: $0.5,1: 1$, and 1: 2 . In each variation has been added titanium dioxide with of $10 \%$ $(\mathrm{w} / \mathrm{v})$ to the polymer solution. The next step is the casting on the glass plate by pouring the mixture. Subsequent evaporation of the solvent slowly to form a membrane. From FT-IR analysis obtained the small bands observed at about $1223 \mathrm{~cm}^{-1}$ corresponding to the asymmetry stretching the external vibrational bands of $\mathrm{SiO}_{4}$ or $\mathrm{AlO}_{4}$. On the other hand, bands around $792 \mathrm{~cm}^{-1}$ and $600 \mathrm{~cm}^{-1}$ are due to the symmetrical stretching of $\mathrm{SiO}_{4}$ or $\mathrm{AlO}_{4}$ and the vibrations of the double rings respectively. The small bands observed at about $600 \mathrm{~cm}^{-1}$ represent a bending mode for $\mathrm{Si}-\mathrm{O}-\mathrm{Si}$. The interaction between sulfonated polysulfone and $\mathrm{TiO}_{2}$ has shown from the widening band of $\mathrm{O}-\mathrm{H}$ bond uptake. Ti-O bonds have shown in the absorption of wave numbers $539.58-516.32 \mathrm{~cm}^{-1}$. Optimum ion exchange analysis obtained $1.003 \mathrm{meq} / \mathrm{g}$ for PSf 0.5 zeolite $10 \% \mathrm{TiO}_{2}$ membrane, the degree of swelling obtained the optimum on the membrane PSf 1.5 zeolite $10 \% \mathrm{TiO}_{2}$ of $0.09 \%$, and methanol permeability was obtained on the membrane PSf 1.0 zeolite $10 \% \mathrm{TiO}_{2}$ of $6.9 \times 10^{-9} \mathrm{~S} / \mathrm{cm}$. The result of optimum proton conductivity for zeolite addition of 1.5 gram at temperature $70^{\circ} \mathrm{C}$ equal to $1.185 \times 10^{-2} \mathrm{~S} / \mathrm{cm}$.
\end{abstract}

Keywords: Composite membrane, sulfonated polysulfone, polysulfone, zeolite, titanium dioxide.

(C) RASĀYAN. All rights reserved

\section{INTRODUCTION}

Techniques in the manufacture of proton conducting membranes can be carried out in several ways, such as modifying an already available membrane in the market, among others, a naphthalized/polyvinyl fluorinesul fonated membrane, sulfonated hydrocarbon polymer, adding a non-solvent or a low volatile solvent, mixing an oxide hygroscopic, and may also add an inorganic compound ${ }^{1}$.

Therefore it is done to improve the existing performance, looking for other alternatives that are cheaper. In an effort to improve membrane performance, one of the ways is to synthesize or manufacture membranes by adding other materials, so membrane performance depends not only on the water content present in the membrane, but also circumstances the protons transport existence can be maintained, Then when methanol is used as a feed, the presence of $\mathrm{CO}$ tolerance by the existing platinum catalyst in the electrode, further implies ions will increase mass transport and increase reaction kinetics ${ }^{2}$.

One polymer having good thermal stability, where the degradation temperature of up to $500^{\circ} \mathrm{C}$ is polysulfone (PSU). With high degradation temperatures, this allows the membrane performance spectrum to be very wide namely it can work at low temperature to temperatures above $100{ }^{\circ} \mathrm{C}$. Previous research has been reported that sulfonated polysulfone has been used in ultrafiltration membrane on ion bonding process through diffusion phenomena or dialysis process of metal ions ${ }^{3}$.

Previous studies have been carried out by sulfonated of polysulfone (SPSU)-added of benzotriazole with proton conductivity up from $3.44 \times 10^{-4}$ to $3.6 \times 10^{-3} \mathrm{~S} / \mathrm{cm}$ at $150^{\circ} \mathrm{C}^{4-5}$.

Another attempt to improve the performance of proton conducting membranes of sulfonated polysulfone is to add activated carbon, as has been reported ${ }^{6}$ with proton conductivity of $8.8 \times 10^{-4} \mathrm{~S} / \mathrm{cm}$ at $40^{\circ} \mathrm{C}$. A recent research report in which polysulfone was added with natural zeolite, its proton conductivity still

Rasayan J. Chem., 12(1), 284-289(2019)

http://dx.doi.org/10.31788/RJC.2019.1215010

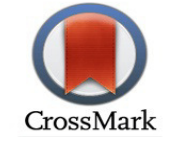


RASĀYAN J. Chem.

Vol. 12 | No. 1 |284 - 289| January - March | 2019

ranges from $7.15 \times 10^{-4} \mathrm{~S} / \mathrm{cm}$ at $40^{\circ} \mathrm{C}^{7}$. The next attempt to improve membrane performance is by adding natural zeolite and titanium dioxide.

In this report discussed is the synthesis and characterization of the composite membranes, the sulfonated polysulfone has been synthesized using the preceding method ${ }^{4,5,6,7}$. Sulfonated polysulfone is further composited with a natural zeolite which is impregnated with titanium dioxide. The composite membrane was evaluated, i.e functional group analysis using FT-IR, ion exchange capacity analysis, the degree of the swelling membrane, methanol permeability, and proton conductivity.

\section{EXPERIMENTAL}

\section{Materials}

Polysulfone (PSU), trimethylsilylchlorosulfonate (TMSCS) and methanol, dimethylformamide and 1, 2dichloroethane, titanium dioxide and natural zeolite.Materials used are the same as previous research reports ${ }^{7}$, except titanium dioxide.

\section{Preparation}

The procedure used is the same as the previous research report ${ }^{7}$, except for the addition of titanium dioxide: sulfonated polysulfone and composite membrane were prepared according to literature ${ }^{4,5,6,7}$. The composite membrane was made by mixing sulfonated polysulfone with natural zeolite as was done in the previous procedure ${ }^{7}$, with the mass ratio of sulfonated polysulfone: zeolite; 1: $0.5,1: 1$, and 1: 2 previously sulfonated polysulfone have been dissolved using dimethyl formamide solvent. The mixture is stirred for 12 hours, at room temperature. In each variation will be added titanium dioxide with a percentage of $10 \%$ of the polymer solution in the previous step. The next step is the casting on the glass plate by pouring the mixture. The solvent was evaporated slowly at $50{ }^{\circ} \mathrm{C}$ for 24 hours then the membrane was transferred into the oven at $65^{\circ} \mathrm{C}$ for 24 hours to evaporate residual solvents still contained in the composite membranes.

\section{Characterization}

FT-IR spectra were recorded on a Bruker Alpha-P (Wismar, Germany) in the range of 4000-400 $\mathrm{cm}^{-1}$. Analysis of ion exchange capacity by titration method, the degree of membrane swelling by the gravimetric method, and methanol permeability by gravimetric method. The conductivity of the membrane was measured by IM 3590 Chemical Impedance Analyzer HIOKI in frequency $1 \mathrm{KHz}, 0.05$ Volt.

\section{RESULTS AND DISCUSSION}

Figure-1 shows the spectra of composite membranes PSF-0,5 ZEOLIT 10\% tion, PSF-1,0 ZEOLIT 10\% $\mathrm{tio}_{2}$, PSF-1,5 ZEOLIT 10\% tio $_{2}$. From spectra showed for composite membranes that have been added zeolites and $\mathrm{TiO}_{2}$, exhibit almost similar pattern spectra. The character of wave numbers for composite membranes is on the broad band in an area of about $1091 \mathrm{~cm}^{-1}$, most prominent in the infrared spectrum, according to the asymmetrical internal stretch of the vibration band $\mathrm{SiO}_{4}$ or $\mathrm{AlO}_{4}$. While the small bands observed around $1223 \mathrm{~cm}^{-1}$ are for asymmetric external vibration bands of $\mathrm{SiO}_{4}$ or $\mathrm{AlO}_{4}$.

The band area around $792 \mathrm{~cm}^{-1}$ and $600 \mathrm{~cm}^{-1}$ caused by symmetrical stretches of $\mathrm{SiO}_{4}$ or $\mathrm{AlO}_{4}$ and vibrations of each double ring. The small bands observed at about $600 \mathrm{~cm}^{-1}$ represent a bending mode for $\mathrm{Si}-\mathrm{O}-\mathrm{Si}$. The interaction between sulfonated polysulfone and $\mathrm{TiO}_{2}$ is shown from the widening band of O$\mathrm{H}$ bond uptake. Ti-O bonds are shown in the absorption of wave numbers $539.58-516.32 \mathrm{~cm}^{-1}$. The previous study on infrared titania sol-gel reported that an infrared band around $805 \mathrm{~cm}^{-1}$ related (Ti-O) vibration mode ${ }^{8}$.

Figure-2 showed ion exchange capacity of composite membranes PSF-0,5 ZEOLIT $10 \%$ tion, PSF-1,0 ZEOLIT $10 \% \mathrm{tio}_{2}$, PSF-1,5 ZEOLIT $10 \% \mathrm{tio}_{2}$. The ion exchange capacity analysis aims to determine the ability of the composite membrane in exchange for the ion bonded to the sulfonate group with other ions given to the system. As an alternative polymer material for making electrolytic membranes, sulfonated polysulfone must have the ability to exchange ions properly to improve the performance of fuel cells. The more the number of ions that can be exchanged the greater the electrical energy generated. Increased ion exchange capacity is proportional to the high degree of sulfonation in a polymer. The number of sulfonate 
groups entering the polymer chain, the more interchangeable $\mathrm{H}^{+}$. The ion exchange capacity shows an amount equivalent to ions per gram of dry polymer weight. In the following curves are shown membrane ion exchange capacity. In Figure-2 showed that the ion exchange capacity obtained in this study is similar to the ion exchange capacity of Nafion $117(0.91 \mathrm{meq} / \mathrm{g})$ membrane ion ${ }^{9}$, the previous study have also reported that membrane ion exchange capacity Nafion 115 which is $0.89 \mathrm{meq} / \mathrm{g}^{10}$.

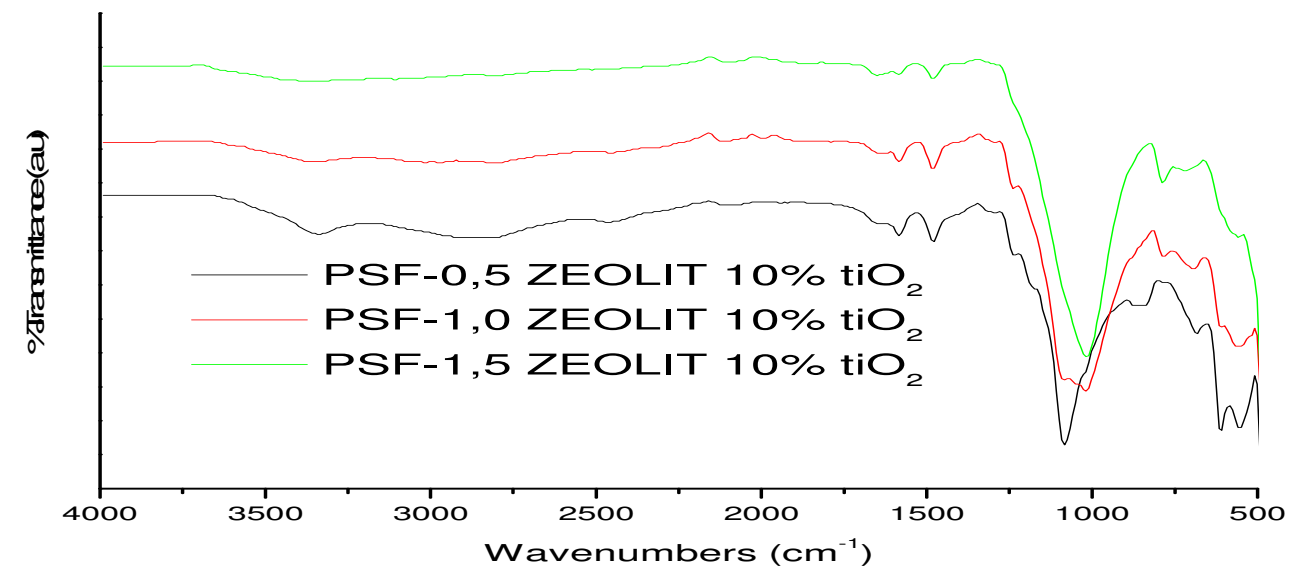

Fig.-1: Spectra of Composite Membranes PSF-0,5 ZEOLIT 10\% Tio 2 , PSF-1,0 ZEOLIT 10\% Tio 2 , PSF-1,5 ZEOLIT $10 \% \mathrm{Tio}_{2}$.

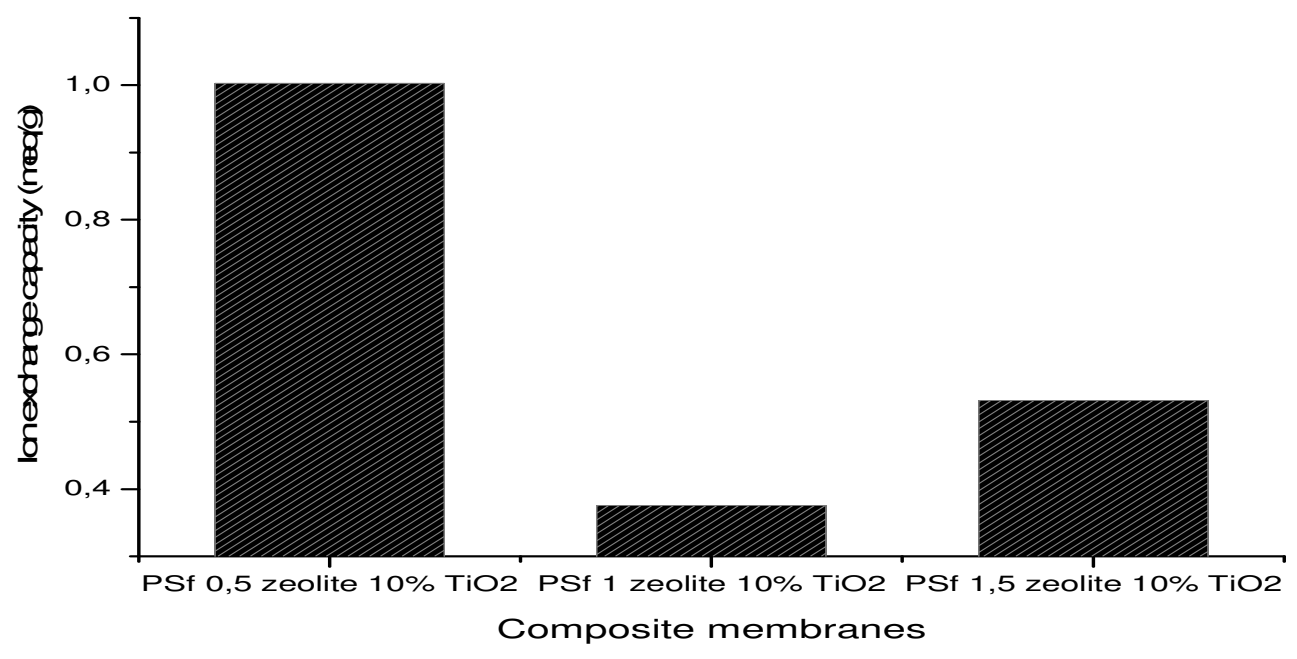

Fig.-2: Ion Exchange Capacity of Composite Membranes PSF-0,5 ZEOLIT 10\% $\mathrm{Tio}_{2}$, PSF-1,0 ZEOLIT 10\% $\mathrm{Tio}_{2}$, PSF-1,5 ZEOLIT $10 \% \mathrm{Tio}_{2}$

Figure-3 showed degree of swelling composite membranes PSF-0,5 ZEOLIT 10\% tion, PSF-1,0 ZEOLIT $10 \% \mathrm{tio}_{2}$, PSF-1,5 ZEOLIT $10 \% \mathrm{tio}_{2}$. The degree of swelling analysis was performed to determine the extent of membrane swelling due to the influence of water absorption. A membrane capable of absorbing water well will affect the resulting proton conductivity value to be greater. This is because the water content of the membrane serves to facilitate the transfer of protons. The greater water content in the membrane causes proton transport to be easier. But the water content is too excessive to cause methanol diffuses through the membrane (methanol crossover) which leads to a decrease in the efficiency of methanol fuel and the efficiency of the cell voltage. Membranes containing many sulfonate groups can improve water absorption capacity with high conductivity, since hydrophilic groups can facilitate proton conductivity at low temperatures. ${ }^{11}$ Methanol permeability analysis aims to determine whether or not methanol can pass through the membrane. As a DMFC electrolyte polymer membrane candidate should 
avoid high permeability of methanol as it may lead to methanol crossover which will decrease overall DMFC performance. The results of the methanol permeability analysis of the composite membrane are shown in the following Fig.-4.

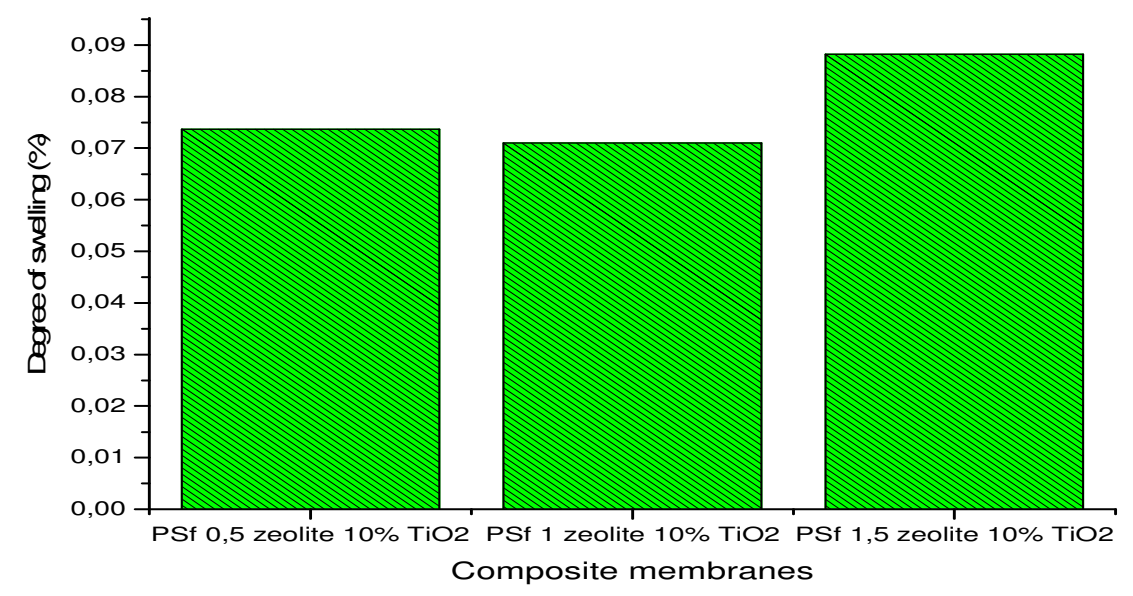

Fig.-3: Degree of Swelling of Composite Membranes PSF-0,5 ZEOLIT 10\% Tio 2 , PSF-1,0 ZEOLIT 10\% Tio 2 , PSF1,5 ZEOLIT $10 \% \mathrm{Tio}_{2}$.

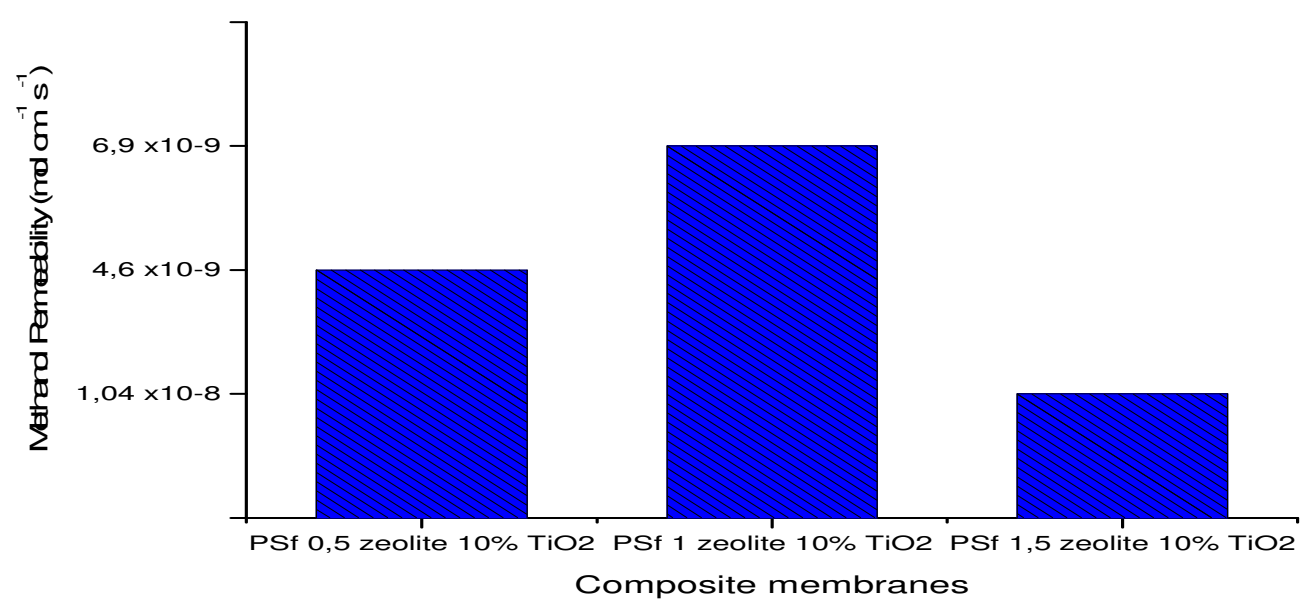

Fig.-4: Methanol Permeability of Composite Membranes PSF-0,5 ZEOLIT 10\% Tio 2 , PSF-1,0 ZEOLIT 10\% Tio, PSF-1,5 ZEOLIT $10 \%$ Tio $_{2}$.

Figure-5 showed The Conductivity of composite membranes PSF-0,5 ZEOLIT $10 \%$ tio 2 , PSF-1,0 ZEOLIT $10 \%$ tio $_{2}$, PSF-1,5 ZEOLIT $10 \%$ tio $_{2}$. The measurements of proton conductivity were carried out at temperatures of $30,50,70$ and $90{ }^{\circ} \mathrm{C}$. Measurements made by increasing the temperature aims to determine the ability of the membrane performance at what temperature the resulting membrane is and see if this composite membrane can work at temperatures close to $100^{\circ} \mathrm{C}$. The objective of the test at temperatures up to $90{ }^{\circ} \mathrm{C}$ to see the effect of impregnants added, whether added important may contribute to the existence of the transport of protons. From the measurements, it is seen that both zeolites and $\mathrm{TiO}_{2}$ added to sulfonated polysulfone are synergistic in increasing the conductivity of the protons, although both still have hydrophilic properties. At high temperatures, the reduced water content decreases the conductivity of the proton. Because generally at low temperatures, the proton conductivity is mostly facilitated by the water content contained or contained in the membrane. At high temperatures that play a role in facilitating the movement of protons is expected to come from impregnants added. Theoretically, the membrane performance at high temperature, the water content has started to evaporate so that the 
RASĀYAN J. Chem.

Vol. 12 | No. 1 |284 - 289| January - March | 2019

proton movement facilitator no longer exists. Therefore with the impregnant, in this case, zeolite and $\mathrm{TiO}_{2}$ can facilitate the movement of protons. The interaction between sulfonated polysulfone to the impregnant zeolite and $\mathrm{TiO}_{2}$ through weak bonds makes it possible for the formation of protonated sites due to impregnant and sulphonated polysulfone relationships.

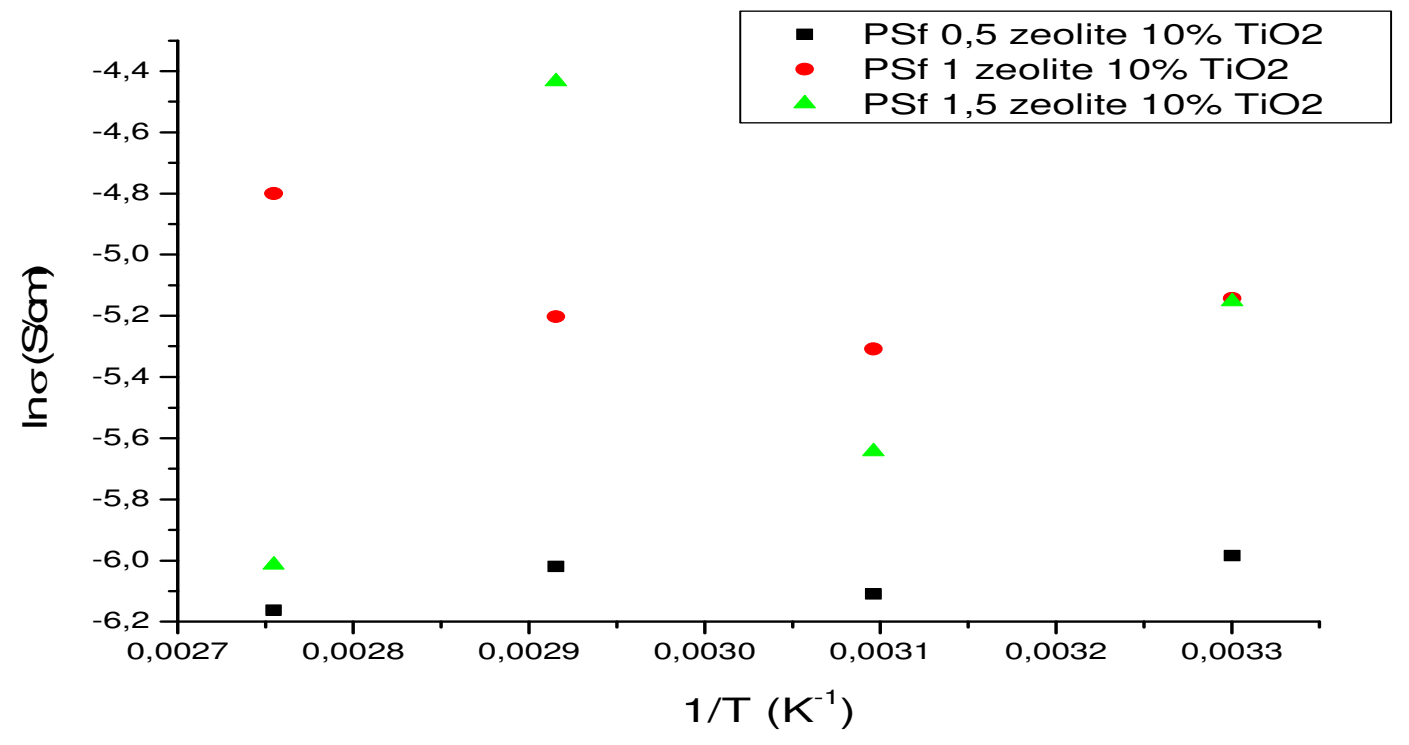

Fig-5: The Conductivity of Composite Membranes PSF-0,5 ZEOLIT 10\% Tio 2 , PSF-1,0 ZEOLIT 10\% Tio 2 , PSF$1,5 \mathrm{ZEOLIT} 10 \% \mathrm{Tio}_{2}$

The weak bonds that occur are non-permanent, allegedly through the process of formation and the breaking of weak bonds leads to proton jumps from one protonated site to the next protonated site. The result of the research shows that the optimum proton conductivity for $\mathrm{TiO}_{2} 10 \%$ occurs with the addition of zeolite 1.5 gram (PSf 1.5 zeolite $10 \% \mathrm{TiO}_{2}$ ) at temperature $70{ }^{\circ} \mathrm{C}$ equal to $1.185 \times 10^{-2} \mathrm{~S} / \mathrm{cm}$, Figure-6 showed a surface section of membrane. For comparison, the proton conductivity of Nafion 117 membrane measured at $60{ }^{\circ} \mathrm{C}$ is $6.7 \times 10^{-2} \mathrm{~S} / \mathrm{cm}$ at a relative humidity of $95 \%{ }^{12}$.

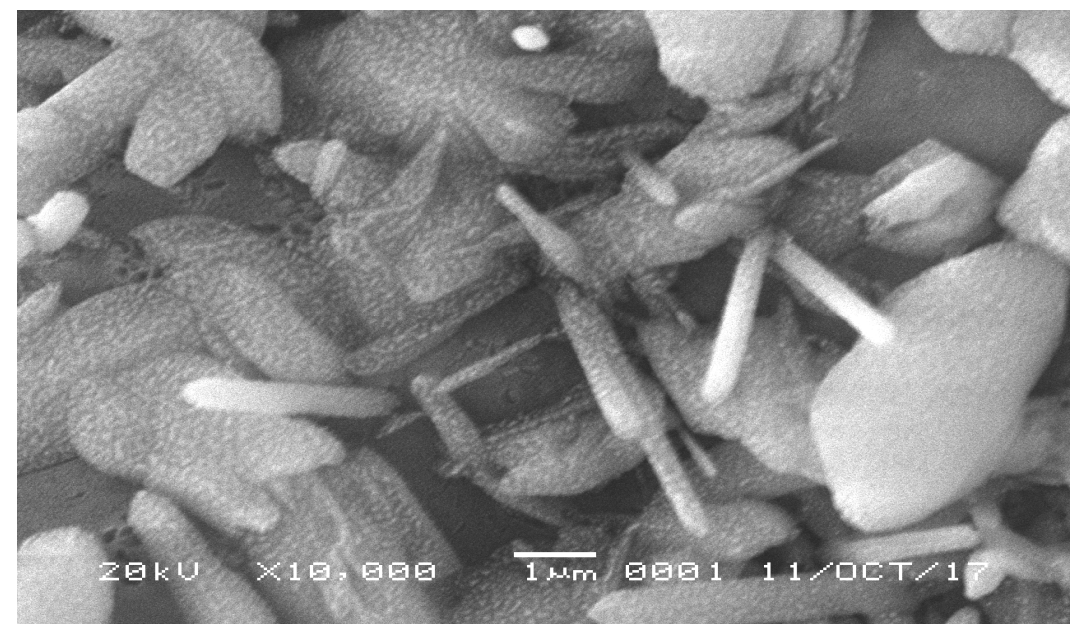

Fig-6: Morphology of Psf $1.5 \mathrm{~g}$ Zeolite $10 \% \mathrm{TiO}_{2}$.

\section{CONCLUSION}

Efforts to improve membrane performance as fuel cell membranes have been conducted. The effort is to combine sulfonated polysulfone with inorganic materials such as natural zeolite and added titanium 
RASĀYAN J. Chem.

Vol. 12 | No. 1 |284 - 289| January - March | 2019

dioxide. The addition of titanium dioxide greatly affects the performance of the obtained conductivity. From the ion exchange, the degree of swelling and methanol permeability showed that the membrane has been produced, close to the category of membranes that have been meticulously or patented as Nafion. Though there are still many shortcomings that need to be improved. From the proton conductivity analysis, it was found that the optimum proton conductivity was obtained from the addition of 1.5-gram zeolite i.e. for composite membrane Psf $1.5 \mathrm{~g}$ zeolite $10 \% \mathrm{TiO}_{2}$ at temperature $70{ }^{\circ} \mathrm{C}$ equal to $1.185 \times 10^{-2}$ $\mathrm{S} / \mathrm{cm}$.

\section{ACKNOWLEDGMENT}

This work is supported through the Ministry of Research, Technology and Higher Education fund of the Republic of Indonesia with contract number 904 / UN30.15 / LT / 2017.

\section{REFERENCES}

1. M. Helen, B. Viswanathan, L. Himakumar and S. Srinivasamurthy, 2006, Photo/Electrochemistry \& Photobiology, In The Environment, Energy And Fuel, Research Signpost, India, pp. 1-42.

2. I. Gustian, S. U. Celik, A. Bozkurt, Advanced Materials Research, 789, 294(2013), DOI: 10.4028/www.scientific.net/AMR.0.294.

3. P. Gryzelda, Ars. Separatoria Acta, 4, 50 (2006).

4. I. Gustian, S. U. Çelik, A. Bozkurt, J. Mater. Res., 27, 2650(2012), DOI: 10.1557/jmr.2012.24.

5. I. Gustian, S. U. Çelik, A. Zainuddin, W. Suratno, A. Bozkurt, R. E. Siregar, J. Math. Fund. Sci., 46, 50(2014), DOI: 10.5614/j.math.fund.sci.2014.46.1.5.

6. I. Gustian, Asdim, E. Maryanti, Rasayan Journal Chemistry, 9 (4), 608 (2016).

7. I. Gustian, Ghufira, D. Oktiarni, Rasayan Journal Chemistry, 10(3), 608 (2017), DOI:10.7324/RJC.2017.1031716.

8. D. C. L. Vasconcelos, V. C. Costa, E. H. M. Nunes, A. C. S. Sabioni, M. Gasparon, W. L. Vasconcelos, Materials Sciences and Appliions, 2, 1375 (2011), DOI:10.4236/msa.2011.210186.

9. B. D. Smitha, D. Anjali, and S. Sridhar, International Journal of Hydrogen Energy, 33, 4138 (2008), DOI: $10.1016 / j$. .jhydene.2008.05.055.

10. W. Li, A. Manthiram, M. D. Guiver, and B. Liu, Electrochemistry Communiions, 12, 607(2010), DOI: $10.1016 /$ j.elecom.2010.02.011.

11. M. M. Mench, Fuel cell engines. John Wiley and Sons. Inc. New York.p 195,196(2008).

12. H. B. Park, H. S. Shin, Y. M. Lee, and J.W. Rhim, Journal of Membrane Science, 247,103(2005), DOI: $10.1016 /$ j.memsci.2004.09.023.

[RJC-5010/2018] 